\title{
Haloaldehyde Polymers. VIII*. Preparation and Polymerization of Dichlorofluoroacetaldehyde
}

\author{
Bunichiro Yamada, ${ }^{* *}$ Richard W. CAMPbell, and O. Vogl \\ Polymer Science and Engineering, University of Massachusetts, \\ Amherst, Mass. 01003, U.S.A.
}

(Received July 5, 1976)

\begin{abstract}
Dichlorofluoroacetaldehyde was prepared from methyl dichlorofluoroacetate by reduction with lithium aluminum hydride. Highly purified dichlorofluoroacetaldehyde was polymerized using various cationic and anionic initiators to a crystalline insoluble polymer or an amorphous soluble polymer, depending on polymerization conditions. It could be stabilized and the thermal degradation behavior was compared with polymers of other perhaloacetaldehydes. The monomer was also copolymerized with other haloacetaldehydes and phenyl jsocyanate.

KEY WORDS Dichlorofluoroacetaldehyde / Dichlorofluoroacetaldehyde Hydrate / Poly(dichlorofluoroacetaldehyde) / Copolymerization with Chloral / Cationic Polymerization / Anionic Polymerization Acetylation / End Capping / Polymer Degradation /
\end{abstract}

Dichlorofluoroacetaldehyde polymerization was studied to learn more about the effects of molecular structure on the physical and chemical properties of perhaloacetaldehydes and their polymers; such as polymerizability, ceiling temperature, crystallinity, and thermal stability, in a series of perhaloacetaldehydes which have been investigated.

Trichloroacetaldehyde, chloral, can be polymerized $^{1-5}$ only to an infusible crystalline polymer insoluble in organic solvents. ${ }^{1,2}$ Trifluoroacetaldehyde, fluoral, has been polymerized to crystalline $^{6-8}$ or a mixture of crystalline and amorphous (presumably atactic) polyacetal depending on polymerization conditions. ${ }^{9}$ This difference in polymerization is apparently caused by the smaller size of the fluorine atoms compared with the chlorine atoms. The crystalline forms of polychloral ${ }^{2}$ and polyfluoral ${ }^{8}$ are presumed to be isotactic polymers. Both polymers have been prepared with anionic and cationic initiators.

It was concluded that in the polymerization

* Part VII: B. Yamada, R.W. Campbell, and O. Vogl, J. Polym. Sci. Chem. Ed., in press.

** On leave from Osaka City University, Osaka, Japan. of chloral the initiator has little or no influence on the stereoregularity of the polymer ${ }^{10}$ and it was, therefore, believed that the size of the side group relative to the length of the bonds of the polymer backbone that are formed during polymerization determined exclusively the stereoregularity of the polymer.

It was of interest to prepare and polymerize the two chlorofluoroacetaldehydes, in this case, dichlorofluoroacetaldehyde, in an attempt to find out how large the side group must be in order for the polymer to form only the isotactic polymer. Recently, difluorochloroacetaldehyde has also been prepared and polymerized. ${ }^{11}$

\section{EXPERIMENTAL}

\section{Materials}

Methyl dichlorofluoroacetate (bp $154^{\circ} \mathrm{C}$, lit. $154^{\circ} \mathrm{C}^{12}$ ) was prepared on a three molar scale by treatment of methyl trichloroacetate with $\mathrm{SbF}_{3}$ in a reaction catalyzed by bromine. ${ }^{12}$ This ester was obtained by the esterification of trichloroacetic acid (Eastman Kodak) with methanol.

\section{Initiators}

Triphenylphosphine $\left(\mathrm{Ph}_{3} \mathrm{P}\right)$ (Aldrich) was purified by recrystallization from benzene. 
Lithium tert-butoxide (LTB) (Alfa Inorganics) was purified by sublimation at $0.1 \mathrm{~mm}$ and $150^{\circ} \mathrm{C}$ prior to use.

Triethyl aluminum (Texan Alkyls), titanium tetrachloride (Fisher Scientific), antimony pentachloride (Alfa Inorganics), sulfuric acid (Fisher Scientific), and dimethylformamide (Eastman Kodak) were used as supplied.

\section{Solvents}

Toluene and dichloromethane were dried with calcium hydride and stored in a nitrogen atmosphere. Methylcyclohexane was distilled from sodium metal and stored under a nitrogen atmosphere. Anhydrous ether (Fisher Scientific) was used directly from freshly opened cans.

\section{Synthesis and Polymerizations}

Reduction of Methyl Dichlorofluoroacetate. Methyl dichlorofluoroacetate $(100 \mathrm{~g}, 0.69 \mathrm{~mol})$ was allowed to react with lithium aluminum hydride $(6.9 \mathrm{~g}, 0.18 \mathrm{~mol})$ according to the procedure described in our earlier paper. ${ }^{11}$ The product was distilled through a 1-ft Vigreux column and the fraction boiling between 57 and $60^{\circ} \mathrm{C}$ at $50 \mathrm{mmHg}$ was collected in $75-\%$ yield. It was found to contain a mixture of the hemiacetal and the hydrate of dichlorofluoroacetaldehyde.

\section{Dichlorofluoroacetaldehyde $\left(\mathrm{CCl}_{2} \mathrm{FCHO}\right)$}

The aldehyde was prepared by dehydration of the above mixture with sulfuric acid. Equal volumes $(10 \mathrm{~m} l)$ of the hydrate mixture and concd sulfuric acid were mixed in a $50-\mathrm{m} l$ round bottom flask and heated under nitrogen. Vigorous stirring was required to effect the formation of a high yield of dichlorofluoroacetaldehyde. The aldehyde was distilled through a 8-inch Vigreux column and collected in 65-\% yield; bp $56^{\circ} \mathrm{C}$. Prior to polymerization the dichlorofluoroacetaldehyde was further purified by trap to trap distillation from phosphorus pentoxide under a reduced pressure of 0.2 $\mathrm{mmHg}$. Gas chromatography showed the aldehyde to contain less than $20 \mathrm{ppm}$ of water.

Anal. Calcd for $\mathrm{C}_{2} \mathrm{HCl}_{2} \mathrm{FO}: \mathrm{C}, 18.35 ; \mathrm{H}$, $0.77 ; \mathrm{F}, 14.51$. Found: C, 18.61; H, 0.77; F, 14.45 .

The infrared spectrum of dichlorofluoroacetaldehyde showed bands at $2855 \mathrm{~cm}^{-1}$ for the aldehyde hydrogen and $1772 \mathrm{~cm}^{-1}$ for the carbonyl stretching. These were observed in either carbon tetrachloride or hexane.

In addition a band at $1363 \mathrm{~cm}^{-1}$ (in plane $\mathrm{C}-\mathrm{H}$ bending) and others at 1182, 1104, 1058, $1000,967,783$, and $623 \mathrm{~cm}^{-1}$ (probably due to carbon-halogen vibrations) are observed.

The corresponding main absorptions for chloral were at 2850 and $1767 \mathrm{~cm}^{-1}$.

The PMR and ${ }^{19} \mathrm{~F}$ NMR spectra were recorded for a 10-\% solution of dichlorofluoroacetaldehyde in carbon tetrachloride. The aldehydic proton was split by the fluorine of the adjacent dichlorofluoromethyl group into a doublet at $9.15 \mathrm{ppm}$, relative to tetramethylsilane. The coupling constant, $J_{\mathrm{H}-\mathrm{F}}=5.0 \mathrm{~Hz}, 0.32 \mathrm{ppm}$ was downfield from an external trifluoroacetic acid lock signal.

Dichlorofluoroacetaldehyde 2,4-Dinitrophenylhydrazone. $\left[\mathrm{CCl}_{2} \mathrm{FCH}=\mathrm{NNHC}_{6} \mathrm{H}_{4}\left(\mathrm{NO}_{2}\right)_{2}\right]$ was prepared according to the method of Ross and Ring $^{13}$ which is specifically used for the preparation of 2,4-dinitrophenylhydrazones of haloacetaldehydes.

A solution of 2,4-dinitrophenylhydrazine $(1 \mathrm{~g}$ in $20 \mathrm{ml}$ concd $\mathrm{HCl}$ ) at $45^{\circ} \mathrm{C}$ was added to a stirred solution of dichlorofluoroacetaldehyde hydrate $(1.3 \mathrm{~g}$ in $2-\mathrm{m} l$ concd $\mathrm{HCl})$. After stirring for $2 \mathrm{hr}$ at room temperature, the mixture was chilled and the yellow crystalline precipitate was collected by filtration, washed with water, recrystallized from ethanol, and dried $\mathrm{mp} 127^{\circ} \mathrm{C}$.

Anal. Calcd for $\mathrm{C}_{8} \mathrm{H}_{5} \mathrm{Cl}_{2} \mathrm{FN}_{4} \mathrm{O}_{4}: \mathrm{C}, 30.67 ; \mathrm{H}$, $1.61 ; \mathrm{N}, 17.88$. Found: C, 30.45; H, 1.93; N, 17.79 .

\section{Dichlorofluoroacetaldehyde Hydrate}

Water was added in one microliter increments to a $10 \%$ solution of dichlorofluoroacetaldehyde in chloroform in an NMR tube and the NMR spectra were recorded. The resulting product was the stable hydrate, as shown by the appearance of two peaks: a doublet at $5.27 \mathrm{ppm}$ $\left(J_{\mathrm{H}-\mathrm{F}}=3.0 \mathrm{~Hz}\right)$ and a singlet in the range 4.5 $5.2 \mathrm{ppm}$, depending on concentration corresponding to the hydroxyl protons. The integrated intensity of the two absorptions was $1: 2$, respectively. Each injection of water caused the aldehyde proton signal to decrease and the two hydrate resonances to increase in amplitude. Substitution of deuterium oxide $\left(\mathrm{D}_{2} \mathrm{O}\right)$ for the 
water resulted in the same observations, except that the hydroxyl resonances were not observed due to the replacement of their protons by deuterium. The ${ }^{19} \mathrm{~F}$ spectra in each case consisted of a doublet $1.58 \mathrm{ppm}$ upfield from an external lock of trifluoroacetic acid, $J_{\mathrm{H}-\mathrm{F}}=3.0 \mathrm{~Hz}$.

\section{Polymerization}

All the polymerizations of dichlorofluoroacetaldehyde were carried out in sealed tubes. The initiator solution was sealed in a small vial and placed into the larger polymerization ampule. The monomer and the desired solvent were vacuum distilled into the ampule and the ampule was sealed at $0.1 \mathrm{mmHg}$. The sealed tube was heated to the desired temperature and the vial containing the initiator solution was broken by shaking the ampule vigorously.

A typical polymerization experiment was as follows: The initiator solution of $\mathrm{Ph}_{3} \mathrm{P}(0.013 \mathrm{~g}$ in $0.2 \mathrm{ml}$ toluene) was sealed in a small vial $(5 \mathrm{~mm} \times 20 \mathrm{~mm})$ which was then placed into a clean flamed-out polymerization ampule $(18 \mathrm{~mm} \times$ $200 \mathrm{~mm})$. Dichlorofluoroacetaldehyde $(1.5 \mathrm{~g})$ and solvent, if any, were distilled at $0.1 \mathrm{mmHg}$ into the ampule, which was cooled in liquid nitrogen, and the ampule was sealed. The ampule was then heated to $75^{\circ} \mathrm{C}$ and shaken vigorously in order to break the initiator ampule. Because the initiator ampule had been sealed under a nitrogen atmosphere at room temperature, it broke readily and dispersed the initiator solution immediately in the monomer to give a homogeneous solution. The reaction was kept at $30^{\circ} \mathrm{C}$ for $46 \mathrm{hr}$, after which time the contents of the ampule had solidified. The tube was opened and the contents poured into $25 \mathrm{~m} l$ of acetone and stirred for $24 \mathrm{hr}$. The suspension was filtered and the insoluble polymer was collected on a sintered glass funnel and dried under reduced pressure.

Anal. Calcd for $\mathrm{C}_{2} \mathrm{HCl}_{2} \mathrm{FO}: \mathrm{C}, 18.35 ; \mathrm{H}$, $0.77 ; \mathrm{F}, 14.51$. Found: C, 18.48; H, 0.89; F, 14.39.

The IR spectrum of the raw polymer $(\mathrm{KBr})$ showed absorptions at; $3380 \mathrm{~cm}^{-1}$ (hydroxyl end groups); $2948 \mathrm{~cm}^{-1}$ (C-H stretching); 1360 and $1338 \mathrm{~cm}^{-1}$ (C-H bending); plus carbon-halogen vibrations at $1158,1120,1060,975,870$, and $703 \mathrm{~cm}^{-1}$. The spectra of the soluble and in- soluble fractions are indistinguishable.

The filtrate was poured into $200 \mathrm{ml}$ of ice water to precipitate any acetone-soluble polymer.

Experiments carried out with the same experimental procedure but under different conditions are summarized in Table II.

Acetylation of the polymers of dichlorofluoroacetaldehyde was carried out with acetic anhydride in order to increase the thermal stability of the polymers. In a dried test tude, $100 \mathrm{mg}$ of powdered polymer and $2 \mathrm{ml}$ of freshly distilled acetic anhydride were allowed to react at room temperature for $48 \mathrm{hr}$, which was sufficient time to achieve acetylation. Acetone-insoluble polymer was also insoluble in acetic anhydride and was isolated by filtration through a sintered glass funnel. The polymer was further purified by extraction with acetone in a Soxhlet apparatus for $48 \mathrm{hr}$ and was then dried under reduced pressure. The acetone-soluble polymer was isolated from the acetylation mixture by pouring it into $100 \mathrm{~m} l$ of ice and the polymer was filtered and purified by an additional precipitation from an acetone solution with water.

Copolymerizations of dichlorofluoroacetaldehyde with chloral and chlorodifluoroacetaldehyde as well as with phenyl isocyanate were carried out in a similar manner to the homopolymerization described above.

\section{Measurements}

Infrared spectra were measured on a PerkinElmer 257 spectrophotometer or on a PerkinElmer 727 Infracord.

NMR spectra of dichlorofluoroacetaldehyde and the soluble polymer portion were recorded on a Perkin-Elmer R-32 $90-\mathrm{MHz}$ spectrometer.

The GC analyses were carried out on a Varian Aerograph 920 Chromatograph under the following conditions: $3 \mathrm{ft} \times 1 / 4$-inch column packed with 80/100-mesh Porapak Q; column temperature, $130^{\circ} \mathrm{C}$; injector temperature, $190^{\circ} \mathrm{C}$; detector temperature, $205^{\circ} \mathrm{C}$. The retention time for the dichlorofluoroacetaldehyde was $250 \mathrm{sec}$ and for water was $55 \mathrm{sec}$.

Differential thermogravimetric analysis was used to characterize and compare the thermal stability of polydichlorofluoroacetaldehyde prepared by different techniques. A Perkin-Elmer TGS-1 thermobalance was used with a sample 
size of about $10 \mathrm{mg}$ in a nitrogen atmosphere and at a heating rate of $5^{\circ} \mathrm{C} / \mathrm{min}$ to determine the thermal degradation spectrum and the maximum degradation rate temperature in regular (TGA) and differential (DTG) modes of operation.

Isothermal pyrolysis of polydichlorofluoroacetaldehyde was carried out in a $18 \mathrm{~mm} \times 100$ $\mathrm{mm}$ ampule with a $10 \mathrm{~mm} \times 300 \mathrm{~mm}$ L-shaped side arm to determine and identify the degradation products. The polymer sample $(100-300$ $\mathrm{mg}$ ) was placed in the ampule and the system was evacuated and sealed under $0.2-\mathrm{mmHg}$ pressure. The end of the tube which contained the sample was heated in a sand bath at 250$300^{\circ} \mathrm{C}$ for several hours until the sample had completely degraded; then the degradation products were collected in the side arm which was cooled to dry ice or liquid nitrogen temperature. After completing the degradation, which is easily observed by the complete disappearance of the polymer, the colorless liquid in the side arm was identified by gas chromatography as the monomer of greater than 95-\% purity. Additional identification of the degradation product was carried out by NMR spectroscopy in carbon tetrachloride solution.

\section{RESULTS AND DISCUSSION}

Dichlorofluoroacetaldehyde has been prepared in a sequence of four steps and an overall yield of $20 \%$.

Trichloroacetic acid was esterified in $75-\%$ yield with methanol catalyzed by sulfuric acid. Methyl trichloroacetate was converted to methyl

$$
\begin{aligned}
& \text { SYNTHESIS OF } \mathrm{CCl}_{2} \mathrm{FCHO}
\end{aligned}
$$

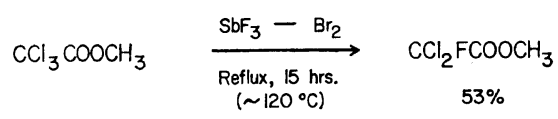

$$
\begin{aligned}
& \mathrm{CCl}_{2} \mathrm{FCOOCH}_{3} \underset{-78^{\circ}, \text { Ether }}{\stackrel{\mathrm{LiALH}_{4}}{\longrightarrow}} \stackrel{\mathrm{H}_{2} \mathrm{O}}{\longrightarrow} \mathrm{CCl}_{2} \mathrm{FCH}(\mathrm{OH})_{2} .
\end{aligned}
$$

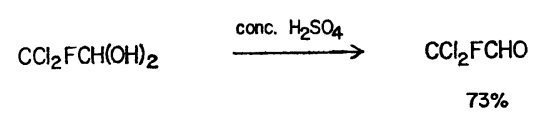

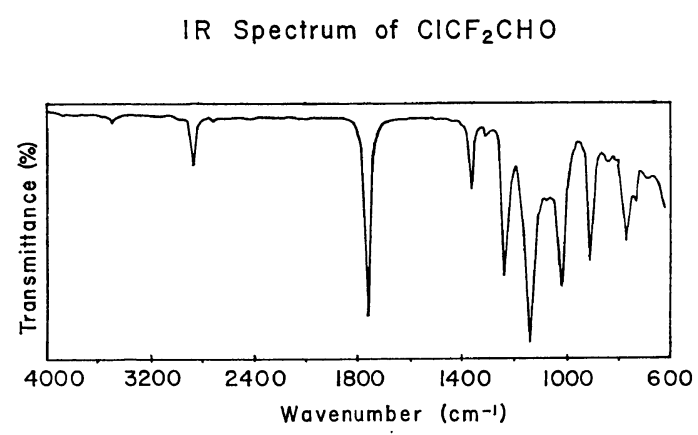

Figure 1. Infrared spectrum of dichlorofluoroacetaldehyde.

Table I. Physical properties of $\mathrm{CCl}_{2} \mathrm{FCHO}$

\begin{tabular}{ll}
\hline bp & $56^{\circ} \mathrm{C}$ \\
IR carbonyl absorption & $1772 \mathrm{~cm}^{-1}$ (in $\mathrm{CCl}_{4}$ ) \\
PMR chemical shift relative & $9.15 \mathrm{ppm}$ (in $\mathrm{CCl}_{4}$ ) \\
to TMS & $J_{\mathrm{H}-\mathrm{F}=5.0 \mathrm{~Hz}}$ \\
mp of & $127^{\circ} \mathrm{C}$ \\
2,4-dinitrophenylhydrazone & \\
\hline
\end{tabular}

dichlorofluoroacetate with $\mathrm{SbF}_{3}$ in the presence of bromine as the catalyst in more than 50-\% yield. The ester was reduced with lithium aluminum hydride to the corresponding aldehyde, whose hydrate was isolated in almost 50-\% yield. The hydrate was then dehydrated with sulfuric acid and the aldehyde purified by repeated distillation from phosphorus pentoxide to obtain polymerization grade monomer.

Other more direct ways for the preparation of dichlorofluoroacetaldehyde, for example, an attempted displacement of one chlorine atom of chloral with a fluorine atom using a fluoride ion from an alkali metal fluoride, failed to give the desired reaction product. In separate experiments it has been noticed that radioactivity could be introduced into chloral when it was treated with ${ }^{35} \mathrm{Cl}^{\ominus}$ in a nucleophilic displacement reaction with ammonium or phosphonium chlorides.

Dichlorofluoroacetaldehyde (I) was characterized by its elemental analysis, its dinitrophenylhydrazone, and also by its NMR and IR spectra (Figure 1), (Table I).

Polymerization of $(\mathbf{I})$ to $\operatorname{poly}(\mathbf{I})$ was attempted with initiators which have been to know give polychloral from chloral by an anionic or cationic mechanism. Using LTB, an apparent anionic 
initiator, at an initiator concentration of 0.8 mol $\%$ at $25^{\circ} \mathrm{C}$ gave insoluble poly(I) at $80-\%$ conversion when the reaction was terminated after 5 days. No soluble fraction was observed. A more extensive study of the polymerization of (I) was done with $\mathrm{Ph}_{3} \mathrm{P}$ as the initiator. At $30^{\circ} \mathrm{C}$ and an initiator concentration of $0.2 \mathrm{~mol} \%$, a 77\% yield of acetone-insoluble polymer was obtained. At $-5^{\circ} \mathrm{C}$ the total yield was $80 \%$, of which $10 \%$ was acetone-soluble. At $-78^{\circ} \mathrm{C}$ and with $0.2-\mathrm{mol} \% \mathrm{Ph}_{3} \mathrm{P}$, the total yield of poly $(\mathbf{I})$ was $70 \%$, of which $15 \%$ was acetone-soluble.

It is believed that the polymerization of $(\mathbf{I})$ with these initiators is caused in a similar way to the polymerization of chloral. The inition step, therefore, would be the addition of tertbutoxide ion to the carbonyl carbon of (I) in the case of LTB and the addition of chloride ion to $(\mathbf{I})$ in the case of $\mathrm{Ph}_{3} \mathrm{P} .{ }^{14}$ The propagation of this polymerization is undoubtedly via the alkoxide ion to form the polyacetal (eq 1).

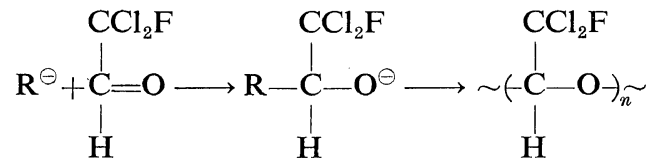

We have made no attempts to identify specifically the termination of this polymerization other than to characterize the final polymer before and after acetylation by thermal degradation.

Polymerization of (I) with typical cationic initiators has also been studied. These initiators gave exclusively acetone-insoluble polymers. With antimony pentachloride at $0.6-\mathrm{mol} \%$ concentration at $-78^{\circ} \mathrm{C}$, approximately $80-\%$ yield of insoluble poly(I) was obtained after $1 \mathrm{hr}$. However, with $\mathrm{TiCl}_{4}$ as the initiator at $0.2 \mathrm{~mol} \%$ at $30^{\circ} \mathrm{C}$ an insoluble polymer was isolated in $32 \%$ yield after $2 \mathrm{hr}$, but no polymer was observed after 8 days at $-78^{\circ} \mathrm{C}$, with $\mathrm{H}_{2} \mathrm{SO}_{4}$ as initiator, $82 \%$ of insoluble polymer was isolated after $46 \mathrm{hr}$ but no polymer was obtained after 5 days at $-78^{\circ} \mathrm{C}$. Boron trifluoride etherate at $3-\mathrm{mol} \%$ concentration at $-5^{\circ} \mathrm{C}$ gave, after $48 \mathrm{hr}, 13-\%$ of insoluble poly(I) and $\mathrm{AlCl}_{3} 25-\%$ at $-5^{\circ} \mathrm{C}$. Cationic polymerization is believed to be initiated by and to propagate through an oxonium ion (eq 2).
Table II. Conditions of $\mathrm{CCl}_{2} \mathrm{FCHO}$ polymerization

\begin{tabular}{|c|c|c|c|c|}
\hline \multicolumn{2}{|c|}{ Initiator } & \multicolumn{2}{|c|}{ Polymerization } & \multirow{2}{*}{$\begin{array}{l}\text { Conver- } \\
\text { sion, } \%\end{array}$} \\
\hline Type & $\underset{\text { mol } \%}{\text { Amount }}$ & $\underset{{ }^{\circ} \mathrm{C}}{\mathrm{Temp}}$ & $\underset{\mathrm{hr}}{\text { Time }}$ & \\
\hline $\mathrm{Ph}_{3} \mathrm{P}$ & 0.2 & -78 & 48 & $55,(16)^{\mathrm{a}}$ \\
\hline $\mathrm{Ph}_{3} \mathrm{P}$ & 0.4 & -5 & 48 & $70,(10)^{\mathrm{a}}$ \\
\hline $\mathrm{Ph}_{3} \mathrm{P}$ & 0.2 & 30 & 48 & 77 \\
\hline LTB & 0.2 & -78 & 48 & 5 \\
\hline LTB & 0.8 & 25 & 2 & 85 \\
\hline $\mathrm{Al}\left(\mathrm{C}_{2} \mathrm{H}_{5}\right)_{3}$ & 0.5 & -78 & 24 & 62 \\
\hline Pyridine & 0.5 & -78 & 1 & 12 \\
\hline DMF & 0.5 & -78 & 1 & 29 \\
\hline $\mathrm{SbCl}_{5}$ & 0.6 & -78 & 1 & 79 \\
\hline $\mathrm{TiCl}_{4} \mathrm{~b}$ & 0.2 & 25 & 2 & 32 \\
\hline $\mathrm{H}_{2} \mathrm{SO}_{4}{ }^{\mathrm{b}}$ & 0.7 & 25 & 46 & 82 \\
\hline $\mathrm{BF}_{3} \cdot \mathrm{O}\left(\mathrm{C}_{2} \mathrm{H}_{5}\right)_{2}{ }^{\mathrm{c}}$ & 3.0 & -5 & 48 & 13 \\
\hline $\mathrm{AlCl}_{3} \mathrm{~d}$ & 1.2 & -5 & 72 & 24 \\
\hline
\end{tabular}

a Acetone soluble polymer.

b No polymer after 5 days at $-78^{\circ} \mathrm{C}$.

c $50 \%$ methylene chloride solution.

d Initiator not soluble in reaction mixture.<smiles>[R6]OC([R6]C([2H])C(Cl)Cl)C(Cl)(Cl)Cl</smiles>

When the initiating species was a proton, for example, when sulfuric acid was used as the initiator, at least one end of the polymer chain was known to be a hydroxyl group. This was confirmed by infrared and end capping studies.

No systematic studies have yet been made to relate the type of initiator, initiator concentration, polymerization temperature, and polymerization time to the conversion of (I) to poly(I) and the tacticity of the polymer (Table II).

Poly(I) is a poly(oxymethylene) substituted with a dichlorofluoromethyl group. We have shown that cationic initiators as well as anionic initiators are effective for the polymerization of $(\mathbf{I})$. The rate of polymerization, or better, the rate of conversion of $(\mathbf{I})$ to poly(I) was not determined, but it seems to be much slower and more erratic than in the case of the polymerization of chloral. Our studies of polymerization conditions and the selection of the type and concentration of initiators are qualitative in- 


\section{IR Spectra of Poly- $\mathrm{FCCl}_{2} \mathrm{CHO}$}

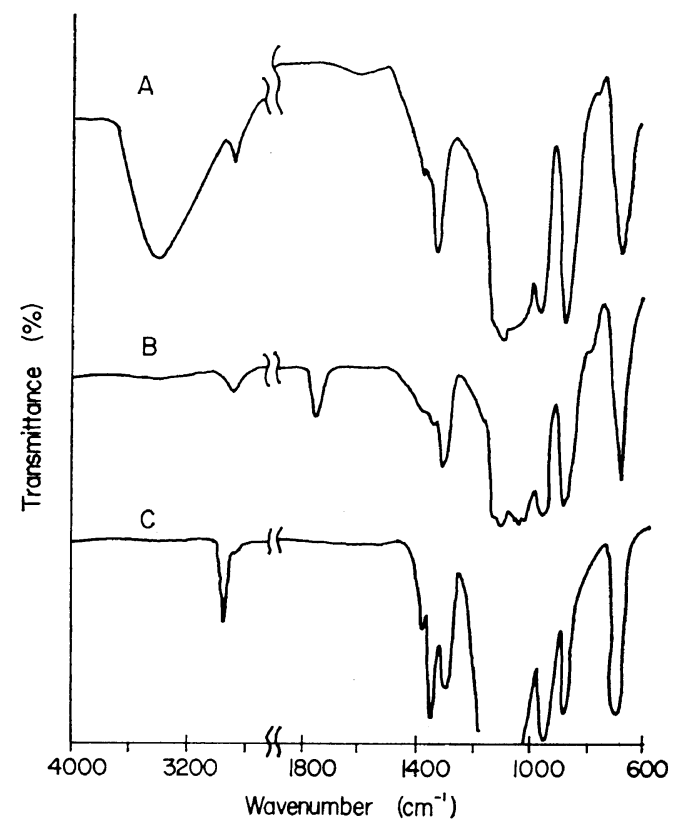

Figure 1A. Infrared spectra of polymers of dichlorofluoroacetaldehyde: $\mathrm{A}, \mathrm{H}_{2} \mathrm{SO}_{4}$ initiated polymer, before acetylation; $\mathrm{B}, \mathrm{H}_{2} \mathrm{SO}_{4}$ initiated polymer, after acetylation; C, LTB initiated polymer from cryotachensic polymerization.

vestigations and no specific effort was made to produce optimum yields.

The characterization of poly $(\mathbf{I})$ was carried out by the interpretation of the infrared spectra and its thermal degradation behavior. For the soluble material, which was only obtained in the case of $\mathrm{Ph}_{3} \mathrm{P}$ initiation and polymerization at temperatures below $0^{\circ} \mathrm{C}$, an NMR spectrum was also taken. For both the soluble and insoluble fractions of poly $(\mathrm{I})$, stabilization experiments were undertaken, followed by infrared and degradation studies of the stabilized samples.

The infrared spectra of poly(I) showed generally the spectrum of a poly(oxymethylene) substituted with the dichlorofluoromethyl group. The spectra in Figure 1A showed the appearance of strong bands in the range of 1000 to 1200 $\mathrm{cm}^{-1}$, which are due to $\mathrm{C}-\mathrm{O}$ bands and to C-F bands. No carbonyl band was observed in the spectra of the untreated polymers, A and C. Some of the raw polymers, particularly those initiated with sulfuric acid or $\mathrm{Ph}_{3} \mathrm{P}$ initiated polymers which were worked up in the presence of water, showed free hydroxyl bands around $3400 \mathrm{~cm}^{-1}$, as seen in Figure $1 \mathrm{~A}-\mathrm{A}$. Acetylation with acetic anhydride transformed this end group into an acetate end group characterized by a carbonyl absorption at $1745 \mathrm{~cm}^{-1}$ and the disappearance of the absorption in the $3400 \mathrm{~cm}^{-1}$ region.

Poly(I) prepared by the LTB initiated cryotachensic polymerization of a $10-\%$ toluene solution of I showed no hydroxyl end groups (Figure 1A-C). This polymer could not be acetylated successfully.

As indicated before, a soluble $\operatorname{poly}(\mathbf{I})$ fraction was obtained with $\mathrm{Ph}_{3} \mathrm{P}$ initiator at lower temperatures. Acetylated soluble poly(I) gave PMR spectra whose proton resonances were a small peak at $2 \mathrm{ppm}$ representing the methyl protons of the acetate end group, and the main peak, a complicated muliplet at $5.3 \mathrm{ppm}$ corresponding to the acetal proton resonances. The complexity of this multiplet is caused by the splitting of the acetal proton by the fluorine atom on the $\alpha$-carbon atom and is probably additionally complicated by the stereochemistry of the asymmetric acetal proton, showing indications of the possible presence of more than one tactic structure.

The soluble fraction of the poly(I) is only an

$$
\begin{aligned}
& \text { NMR Spectrum of Soluble } \\
& \text { Poly }-\mathrm{FCCl}_{2} \mathrm{CHO}
\end{aligned}
$$

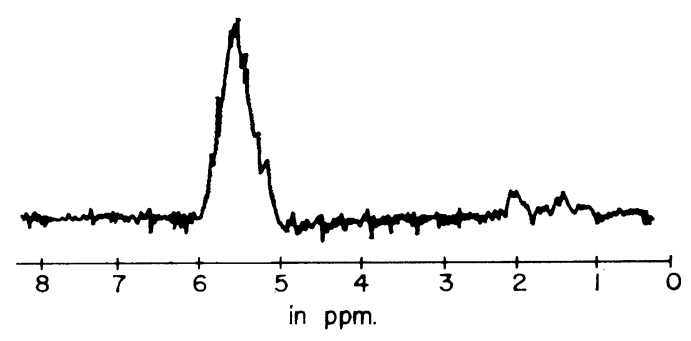

Figure 2. PMR spectrum of soluble poly(dichlorofluoroacetaldehyde): Initiated with $\mathrm{Ph}_{3} \mathrm{P}$ as initiator; polymerization bath temperature, $-5^{\circ} \mathrm{C}$; solvent, carbon tetrachloride. 
Haloaldehyde Polymers. VIII.

oligomer, because calculations of the intensity of the acetal proton with regard to the intensity of the methyl protons of the acetyl end group indicated that this material has an average degree of polymerization of approximately 8 . Vapor phase osmometry $\left(37^{\circ} \mathrm{C}\right.$ in chloroform) showed the number average molecular weight to be about 1400 or a DP of about 11. NMR studies at higher temperatures and high resolution are necessary to establish more clearly the stereochemistry of this oligomer. The stiffness of the polymer chain, which causes extensive line broadening of the actual protons because of only partial averaging, will make this interpretation uncertain.

On the basis of these results, we must conclude that all poly(I) of relatively high molecular weight are insoluble and the solubility of the "acetone soluble polymer" most likely is caused by its being of low molecular weight.

\section{DTG Curves of Poly- $\mathrm{FCCl}_{2} \mathrm{CHO}$}

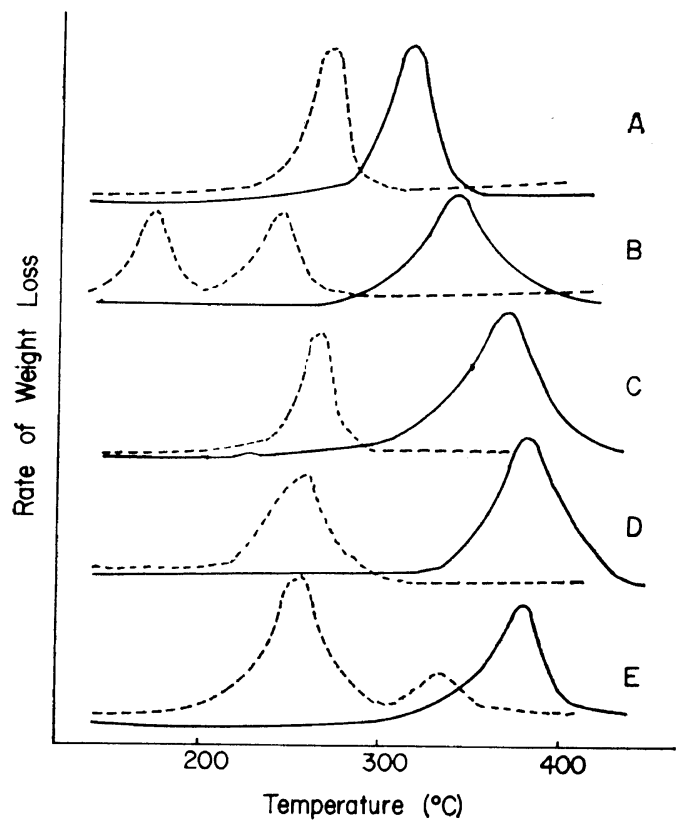

Figure 3. DTG curves of poly(dichlorofluoroacetaldehyde): initiators, $\mathrm{A}, \mathrm{TiCl}_{4}, 30^{\circ} \mathrm{C} ; \mathrm{B}, \mathrm{H}_{2} \mathrm{SO}_{4}$, $30^{\circ} \mathrm{C}$; C, $\mathrm{SbCl}_{5},-78^{\circ} \mathrm{C}$; D, LTB, $30^{\circ} \mathrm{C}$; E, $\mathrm{AlEt}_{3}$, $-78^{\circ} \mathrm{C} ; \cdots,-$, before acetylation, - , after acetylation.
Table III. Maximum degradation temperatures of poly(dichlorofluoroacetaldehyde)

\begin{tabular}{|c|c|c|}
\hline $\begin{array}{l}\text { Polymer end } \\
\text { groups }\end{array}$ & $\begin{array}{c}\text { Initiator } \\
\text { used for } \\
\text { polymerization }\end{array}$ & $\begin{array}{l}\text { Max degradation } \\
\text { rate temperature } \\
\text { ranges, }{ }^{\circ} \mathrm{C}\end{array}$ \\
\hline \multicolumn{3}{|l|}{$\mathrm{CCl}_{2} \mathrm{~F}$} \\
\hline \multirow{2}{*}{$\begin{array}{c}-(\mathrm{C}-\mathrm{O}-)_{n} \mathrm{H} \\
\mathrm{H}\end{array}$} & $\begin{array}{l}\mathrm{LTB}, \mathrm{Al}\left(\mathrm{C}_{2} \mathrm{H}_{5}\right)_{3}, \\
\mathrm{SbCl}_{5}, \mathrm{H}_{2} \mathrm{SO}_{4}, \\
\mathrm{TiCl}_{4}\end{array}$ & 240 to 270 \\
\hline & $\mathrm{Ph}_{3} \mathrm{P}$ & 110 to 150 \\
\hline \multirow[t]{2}{*}{$\underset{\mathrm{H}}{+\mathrm{C}}$} & $\begin{array}{l}\mathrm{LTB}, \mathrm{Al}\left(\mathrm{C}_{2} \mathrm{H}_{5}\right)_{3}, \\
\mathrm{SbCl}_{5}, \mathrm{H}_{2} \mathrm{SO}_{4}, \\
\mathrm{TiCl}_{4}\end{array}$ & 320 to 380 \\
\hline & $\mathrm{Ph}_{3} \mathrm{P}$ & 190 to 240 \\
\hline
\end{tabular}

A preliminary study of the X-ray diffraction of poly $(\mathbf{I})$ showed that the Debye-Scherrer diagrams of insoluble poly $(\mathbf{I})$ and the soluble oligomer were very similar and indicated low to medium crystallinity. The power pattern is similar to powder patterns of polychloral. ${ }^{1}$

Acetylations of unstable hydroxyl end groups have been used in the past to stabilize poly(oxymethylene)s, particularly for the commercial production of poly(formaldehyde). ${ }^{15}$ It has also been used for the improvement of the stability of polyfluoral. ${ }^{8}$ Although acetylation of polychloral has been reported earlier, ${ }^{3}$ polychloral obtained by cryotachensic polymerization ${ }^{2}$ with anionic initiators, for example LTB and $\mathrm{Ph}_{3} \mathrm{P}$, could not be acetylated. ${ }^{16}$

It was one of the objectives of this work to study the thermal stability of raw $\operatorname{poly}(\mathbf{I})$, to attempt then the stabilization by end-capping, and to evaluate the stability of the acetylated polymer. Figure 3 shows DTG curves (obtained by a programmed temperature increase) of $\operatorname{poly}(\mathbf{I})$ prepared under different conditions before and after acetylation. It can be seen that most raw polymers have a maximum rate of weight loss near $250^{\circ} \mathrm{C}$. Generally speaking, these polymers have temperatures of maximum rate of degradation in the range of $240-280^{\circ} \mathrm{C}$. Acetylation of the polymer removed the low peak and increased the stability of the polymer to a maximum degradation rate temperature of $320-380^{\circ} \mathrm{C}$.

Completion of the acetylation was indicated by the good reproducibility of DTG curves after repeated acetylation. A temperature of maxi- 


\section{DTG Curves of Poly- $\mathrm{FCCl}_{2} \mathrm{CHO}$ with $\mathrm{Ph}_{3} \mathrm{P}$}

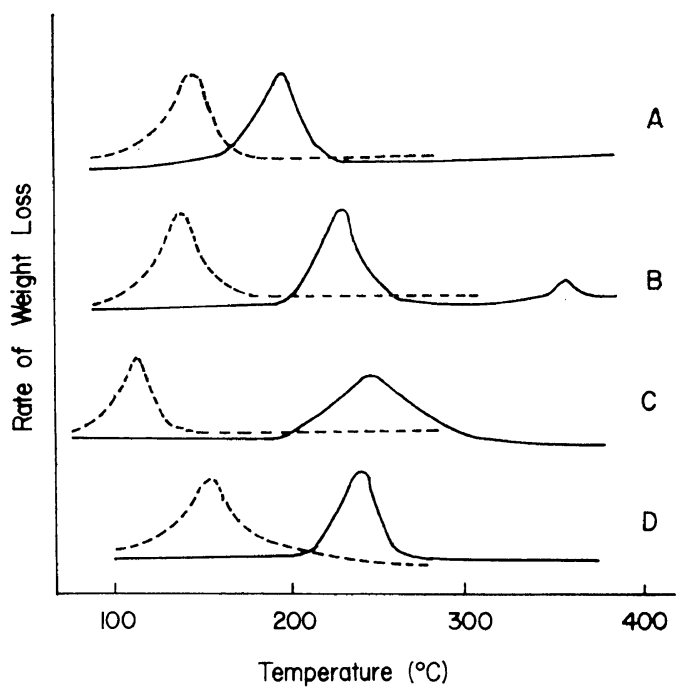

Figure 4. DTG Curves of poly(dichlorofluoroacetaldehyde): initiator, $\mathrm{Ph}_{3} \mathrm{P} ; \mathrm{A}, 30^{\circ} \mathrm{C} ; \mathrm{B},-5^{\circ} \mathrm{C} ; \mathrm{C}$, $-5^{\circ} \mathrm{C}$ (acetone-soluble oligomer); $\mathrm{D},-78^{\circ} \mathrm{C}$; --.-, before acetylation; _-, after acetylation.

mum rate of degradation of $380^{\circ} \mathrm{C}$ indicated that polymer degradation occurred by breakage of the main chain of the polymer rather than by degradation from the chain ends. Polymer degradation studies on polychloral have shown that maximum rate temperatures as high as $385^{\circ} \mathrm{C}$ have been obtained under maximum conditions of stabilization. ${ }^{17}$ It might be noted that the maximum degradation rate temperature for acetylated polyfluoral is also in the same range. ${ }^{7}$

Poly(I) prepared with $\mathrm{Ph}_{3} \mathrm{P}$ as initiator is generally less stable than other poly(I)'s as seen in Table III and Figure 4. Maximum degradation rate temperatures for the raw polymers are in the range of $110-150^{\circ} \mathrm{C}$, depending on the polymerization conditions. After acetylation the maximum degradation rate temperature increased only to the range of $190-240^{\circ} \mathrm{C}$, depending on the individual sample. It is, however, important to realize that the maximum degradation rate temperature of the acetylated or stabilized polymer of dichlorofluoroacetaldehyde obtained from the polymerization with $\mathrm{Ph}_{3} \mathbf{P}$ as the initiator was almost in the same range as the polymer obtained directly with cationic initiators without acetylation. This result indicates that the polymer obtained with $\mathrm{Ph}_{3} \mathrm{P}$ as the initiator has one end group which is relatively labile but could not be acetylated.

We conclude that $\operatorname{poly}(\mathbf{I})$ as prepared by anionic or cationic initiators gives polymers with unstable endgroups. Polymers prepared with sulfuric acid as initiator have hydroxyl endgroups. Samples of poly(I) prepared with other initiators have unstable endgroups of unknown structure or have hydroxyl endgroups which are introduced during the workup of the reaction (precipitation with hydroxylic solvents). In both cases poly(I) samples could be acetylated. The stability of these samples was nearly the same as that for $\operatorname{poly}(\mathbf{I})$ of the highest thermal stability.

In separate experiments the thermal degradation of poly $(\mathbf{I})$ samples was carried out isothermally in the temperature range of $250-300^{\circ} \mathrm{C}$ in vacuo. The degradation products were collected at liquid nitrogen temperature and were obtained in more than $95 \%$ yield. According to NMR and gas chromatography, the degradation product was I of more than $95 \%$ purity. Therefore, the peak in Figures 3 and 4 corresponds to the temperature of maximum rate of monomer formation from the polymer.

Table IV. Conditions of $\mathrm{CCl}_{2} \mathrm{FCHO}$ copolymerization $^{2}$

\begin{tabular}{|c|c|c|c|c|}
\hline $\begin{array}{l}\text { Comono- } \\
\text { mer }\end{array}$ & $\begin{array}{c}\text { Initiatorb }^{b} \\
\text { type }\end{array}$ & $\underset{{ }^{\circ} \mathrm{C}}{\text { Temp }}$ & $\begin{array}{l}\text { Conver- } \\
\text { sion, } \%\end{array}$ & $\begin{array}{c}\mathrm{Mol} \% \\
\mathrm{CCl}_{3} \mathrm{FCHO} \\
\text { in } \\
\text { copolymer }\end{array}$ \\
\hline $\mathrm{CCl}_{3} \mathrm{CHO}$ & $\mathrm{Ph}_{3} \mathbf{P}$ & -5 & $70,(10)^{c}$ & $64,(68)^{\mathrm{c}}$ \\
\hline $\mathrm{CCl}_{3} \mathrm{CHO}$ & LTB & -5 & 0 & - \\
\hline $\mathrm{CCl}_{3} \mathrm{CHO}$ & $\mathrm{SbCl}_{5}$ & -78 & 57 & 55 \\
\hline $\mathrm{CCl}_{3} \mathrm{CHO}$ & $\mathrm{TiCl}_{4}$ & 30 & 50 & 100 \\
\hline $\mathrm{PhNCO}$ & $\mathrm{Ph}_{3} \mathrm{P}$ & -5 & $30,(48)^{c}$ & $100,(93)^{\mathrm{c}}$ \\
\hline $\mathrm{PhNCO}$ & LTB & -5 & 0 & - \\
\hline
\end{tabular}

a $\mathrm{CCl}_{2} \mathrm{FCHO}$ and comonomer equimolar in feed.

b $0.5-\mathrm{mol} \%$ initiator with respect to comonomer mixture.

c Acetone-soluble polymer. 
Aldehyde polymerizations are known for their low ceiling temperatures of polymerizations. Higher aliphatic aldehydes have ceiling temperatures below $0^{\circ} \mathrm{C}$ and the ceiling temperature (one molar monomer solution) of chloral polymerization has recently been determined as 12 or $18^{\circ} \mathrm{C}$, depending on the source of information and possibly depending slightly on the solvent. ${ }^{10,17}$ We have determined the ceiling temperatures $\left(T_{\mathrm{c}}\right)$ of polymerization of several trihaloacetaldehydes in one common solvent-methylcyclohexaneand found the $T_{\mathrm{c}}$ of chloral to be $18^{\circ} \mathrm{C} .{ }^{10}$ Dichlorofluoroacetaldehyde had a $T_{\mathrm{c}}$ of $52^{\circ} \mathrm{C}$ and chlorodifluoroacetaldehyde of $70^{\circ} \mathrm{C} .^{11}$ An earlier report indicated that chlorodifluoroacetaldehyde had a $T_{\mathrm{c}}$ of polymerization of $85^{\circ} \mathrm{C} .{ }^{18}$

Copolymerizations of dichlorofluoroacetaldehyde were carried out with chloral and with phenyl isocyanate. The product compositions were determined by elemental analysis of fluorine or nitrogen.

Dichlorofluoroacetaldehyde copolymerized with chloral with $0.5 \mathrm{~mol} \%$ of either $\mathrm{Ph}_{3} \mathrm{P}$, LTB, $\mathrm{SbCl}_{5}$, or $\mathrm{TiCl}_{4}$ was used as the initiator. The comonomer composition in the feed was approximately $50 \mathrm{~mol} \%$ and the copolymerizations were carried out at various temperatures. $\mathrm{TiCl}_{4}$ at $30^{\circ} \mathrm{C}$ gave pure homopolymer of $\mathrm{I}$ in $50-\%$ conversion. $\mathrm{Ph}_{3} \mathrm{P}$ at $-5^{\circ} \mathrm{C}$ gave a mixture of a soluble oligomer and an insoluble polymer. The insoluble polymer, obtained in $70-\%$ conversion, contained $64-\mathrm{mol} \%$ I. The polymer portion which was soluble in acetone was obtained in $10 \%$ conversion and consisted of a copolymer of $68 \mathrm{~mol} \%$ of I and $32 \mathrm{~mol} \%$ of chloral. With $\mathrm{SbCl}_{5}$ at $-78^{\circ} \mathrm{C}$ an insoluble polymer was obtained in $57-\%$ conversion, which contained $55 \mathrm{~mol} \%$ of $\mathbf{I}$. The results of these copolymerizations indicate that I was more reactive than chloral. Further studies ${ }^{11}$ showed that the order of reactivity was $\mathrm{CClF}_{2} \mathrm{CHO}>$ $\mathrm{CCl}_{2} \mathrm{FCHO}>\mathrm{CCl}_{3} \mathrm{CHO}$.

The thermal stabilities of these copolymers as measured by the DTG maximum rate degradation temperatures were not significantly different from pure poly(I) under the same polymerization conditions and stabilization treatment.

When $\mathrm{Ph}_{3} \mathrm{P}$ was the initiator for the copolymerization of $\mathbf{I}$ with phenylisocyanate at a comonomer feed ratio of $1: 1$ at $-5^{\circ} \mathrm{C}$ a mixture of soluble and insoluble material was obtained. The insoluble fraction, obtained in 30\% yield, consisted of pure poly(I). In addition a copolymer soluble in acetone was obtained at a conversion of $48 \%$, which consisted of an approximately $7-\mathrm{mol} \%$ incorporation of the isocyanate. The molecular weight of the copolymer was, however, very low.

Acknowledgement. This work was supported by a grant from the National Science Foundation, and, in part, from a grant from the Materials Research Laboratory.

\section{REFERENCES}

1. A. Novak and E. Whalley, Trans. Faraday Soc., 55, 1490 (1959).

2. O. Vogl, H.C. Miller, and W. H. Sharkey, Macromolecules, 5, 658 (1972).

3. I. Rosen, C. L. Sturm, G. H. McCain, R. M. Wilhjelm, and D. E. Hudgin, J. Polym. Sci., Part A, 3, 1545 (1965).

4. I. Rosen in "Polyaldehydes," O. Vogl, Ed., Marcel Dekker, New York, N.Y., 1967.

5. O. Vogl, U.S. Patent 3454527 (1969).

6. D. R. Husted and A. H. Ahlbrecht, British Patent 719877 (1954).

7. W. K. Busfield, Polymer, 9, 479 (1968).

8. W. K. Busfield and I. J. McEwen, Eur. Polym. J., 8, 789 (1972).

9. S. Temple and R. L. Thorton, J. Polym. Sci., Part A-1, 10, 709 (1972).

10. O. Vog1, J. Macromol. Sci-Chem., A9, 663 (1975).

11. B. Yamada, R. W. Campbell, and O. Vogl, $J$. Polym. Sci. Chem. Ed., in press.

12. E. Gryszkiewicz-Trochimowphi, A. Sporzynski, and J. Wnuk, Rec. Trav. Chim., 66, 419 (1947).

13. A. Ross and R. N. Ring, J. Org. Chem., 26, 579 (1961).

14. O. Vog1, U.S. Patent 3668184 (1972).

15. D. L. Funck ahd O. Vogl, U.S. Patent 3001 966 (1961).

16. P. Kubisa and O. Vogl, Polym. J., 7, 186 (1975).

17. O. Vogl, IUPAC Symposium on Ring Opening Polymerization, Jablonna, Poland, 1975.

18. I. Mita, I. Imai, and H. Kambe, Makromol. Chem., 137, 143 (1970).

19. W. K. Busfield and I. J. McEwen, Eur. Polym. J., 9, 1143 (1973). 